\title{
Penyuluhan DAGUSIBU dan Penggunaan TOGA Pada Hipertensi Kepada Anggota PKK Danukusuman, Kecamatan Serengan, Kota Surakarta
}

\author{
${ }^{1 *}$ Erindyah R. Wikantyasning, ${ }^{1}$ Shafira Widyanti, ${ }^{1}$ Amalia Septianawati, ${ }^{1}$ Nor Laili, ${ }^{1}$ Devita Dwitama \\ Setya, Sella ${ }^{1}$ Aprilia, ${ }^{1}$ Lusi Anggraini
}

${ }^{1}$ Fakultas Farmasi, Universitas Muhammadiyah Surakarta, Surakarta, Indonesia *Email: erindyah.rw@ums.ac.id

(Received: 24 June 2020/Accepted: 30 June 2020/Published: 8 July 2020)

\begin{abstract}
Abstrak
Hipertensi merupakan salah satu penyakit tidak menular yang menjadi ancaman masyarakat di negara berkembang. Hipertensi disebut silent killer karena gejala yang dialami penderita hampir sama dengan gejala penyakit lain atau tanpa keluhan, sehinga tidak diketahui mengalami hipertensi dan baru diketahui setelah terjadi komplikasi. Danukusuman merupakan kawasan padat penduduk dengan rata-rata usia lebih dari 40 tahun dengan pekerjaan sebagai wirausaha. Penduduk di Danukusuman sebagian mengalami hipertensi. Obat hipertensi digunakan oleh sebagian kecil penduduk, sedangkan sebagian besar tidak mengkonsumsi obat karena takut ketergantungan dalam pengobatan. Selain itu TOGA (tanaman obat keluarga) sebagai pencegahan hipertensi belum diminati di kalangan penduduk Danukusuman. Tujuan kegiatan ini adalah untuk mensosialisasikan tentang penyakit hipertensi, gerakan DAGUSIBU (dapatkan, gunakan, simpan, buang) untuk obat hipertensi, dan pengendalian hipertensi menggunakan TOGA. Kegiatan pengabdian masyarakat untuk ibu-ibu PKK Danukusuman dilaksanakan pada hari minggu tanggal 22 Desember 2019. Kegiatan dilakukan dengan pemberian pretest, pengecekan tekanan darah, penyuluhan tentang hipertensi, DAGUSIBU, tanaman obat keluarga untuk hipertensi, diskusi, dan post test. Dari analisis hasil pretest dan post test diketahui adanya peningkatan yang signifikan tentang pengetahuan ibu-ibu PKK mengenai materi yang disampaikan. Dari kegiatan ini diharapkan adanya keberlanjutan yaitu adanya tindakan pengendalian hipertensi yang lebih baik di kalangan ibu-ibu PKK kelurahan Danukusuman Surakarta.
\end{abstract}

Kata Kunci: DAGUSIBU, hipertensi, TOGA

\section{Abstract}

Hypertension is a non-communicable disease which is a threat to people in developing countries. Hypertension is called silent killer because the symptoms experienced by patients are almost the same as the symptoms of other diseases or without complaints, so it is not known to have hypertension and only known after complications occur. Danukusuman is an area with population with an average age of more than 40 years with employment as an entrepreneur. Some residents in Danukusuman suffer from hypertension. Hypertension drugs are used by a small portion of the population, while most do not consume drugs for fear of dependence in treatment. Besides that, TOGA (tanaman obat keluarga $=$ family medicinal plants) as a prevention of hypertension has not been in demand among Danukusuman residents. The purpose of this activity is to socialize about hypertension, the DAGUSIBU (dapatkan, gunakan, simpan, buang = get, use, save, discard) activity for hypertension medication, and control of hypertension using family medicinal plants. The community service activities for PKK Danukusuman women are held on Sunday, December 22, 2019. The activities are carried out by giving a pretest, checking blood pressure, counseling about hypertension, DAGUSIBU, TOGA for hypertension, discussion, and post-test. From the analysis of the pretest and post-test results, it was found that there was a significant increase in the knowledge of PKK women about the material delivered. From this activity, it is expected that there will be continuity, namely the existence of better hypertension control measures among PKK women in Danukusuman Surakarta village.

Keywords: DAGUSIBU, hypertension, TOGA 


\section{Pendahuluan}

Penyakit hipertensi merupakan salah satu masalah kesehatan di dunia karena prevalensinya tinggi menyebabkan penyakit kardiovaskuler dan penyakit ginjal kronik (Mills et al., 2016). Menurut WHO hipertensi menjadi penyebab kematian yang tidak terdiagnosa. Penderita hipertensi yang tidak terdiagnosa, maka tidak mendapat perawatan sehingga tidak dapat mengontrol tekanan darah dalam jangka panjang mengakibatkan terjadi komplikasi hipertensi dan peningkatan penyakit kardiovaskuler (WHO, 2013).

Di Surakarta penyakit hipertensi masuk pada 10 besar penyakit di Puskesmas. Jika dilihat berdasarkan penyakit tidak menular maka menempati urutan pertama. Kasus yang ditemukan pada 2016 dari laporan Puskesmas sebanyak 59.028 kasus (hipertensi essensial). Terjadi peningkatan jika dibandingkan dengan jumlah kasus tahun 2015 sebanyak 52.637 kasus. Hal ini perlu mendapat perhatian karena menunjukan bahwa pola penyakit degeneratif perlu mendapatkan perhatian yang serius dari semua pihak (DinKes Surakarta, 2017).

Danukusuman merupakan kawasan padat penduduk dengan rata-rata usia lebih dari 40 tahun dengan pekerjaan sebagai wirausaha. Penduduk di Danukusuman sebagian mengalami hipertensi. Obat hipertensi digunakan oleh sebagian kecil penduduk, sedangkan sebagian besar tidak mengkonsumsi obat karena takut ketergantungan dalam pengobatan. Selain itu obat herbal/TOGA sebagai pencegahan hipertensi belum diminati di kalangan penduduk Danukusuman. Mengingat insidensi hipertensi yang terus meningkat dan bahaya komplikasi yang ditimbulkan, maka perlu dilakukan sosialisasi tentang penyakit hipertensi termasuk pemeriksaan tekanan darah di Danukusuman sehingga dapat memantau kondisi kesehatan dengan lebih mudah.

Berdasarkan uraian di atas maka perlu dilakukan sosialisasi tentang cara pengendalian penyakit hipertensi menggunakan TOGA (tanaman obat keluarga) yang banyak tumbuh di sekitar rumah warga, penyuluhan tentang gerakan DAGUSIBU (dapatkan, gunakan, dimpan, buang) untuk obat hipertensi, pemantauan tekanan darah di Danukusuman agar dapat mengontrol tekanan darahnya dengan baik, serta diskusi dan tanya jawab mengenai materi penyuluhan yang telah disampaikan agar warga Dusun Danukusuman dapat memperbaiki kualitas hidup sehari-hari.

\section{Metode}

Kegiatan pengabdian masyarakat ibu-ibu PKK Danukusuman dilaksanakan pada hari minggu tanggal 22 Desember 2019 pukul 16.00 WIB. Acara dimulai dengan pembukaan, dilanjutkan dengan perkenalan kepada ibu-ibu PKK Danukusuman terkait maksud dan tujuan melakukan pengabdian masyarakat. Ibu-ibu PKK Danukusuman rata-rata berusia lanjut. Pelaksanaan kegiatan pengabdian ini bertujuan agar masyarakat lebih mengenal penandaan obat, cara DAGUSIBU (mendapatkan, menggunakan, menyimpan, dan membuang) obat antihipertensi dengan benar sehingga dapat mencegah terjadinya penggunaan obat antihipertensi yang tidak tepat serta meminimalisisasi reaksi yang merugikan akibat obat yang tidak sesuai aturan. Kegiatan ini juga bertujuan untuk memperkenalkan kepada masyarakat mengenai TOGA (tanaman obat keluarga) untuk hipertensi.

Ibu-ibu PKK yang baru datang harus mengisi presensi terlebih dahulu, sembari dibagikan soal pre-test dan leaflet mengenai hipertensi. Setelah itu dilanjutkan pembukaan dan penyampaian tema kegiatan ini. Setelah itu adalah penyampaian materi terkait pengenalan TOGA sebagai antihipertensi dan DAGUSIBU obat antihipertensi. Setelah materi disampaikan, ibu-ibu dipersilakan bertanya kepada pemateri. Pertanyaan yang ditanyakan oleh 6 peserta tercantum pada Tabel 1. Ibu-ibu PKK Danukusuman sangat antusias terhadap materi yang disampaikan. Acara selanjutnya yaitu pembagian soal post-test dengan pertanyaan yang sama seperti soal pretest untuk mengetahui apakah ada peningkatan pemahaman setelah materi disampaikan. Dilakukan analisis uji $\mathrm{t}$ antara jawaban post-test dan jawaban pre-test menggunakan software SPSS. Kegiatan berakhir pada pukul 17.00 WIB dan diakhiri dengan foto bersama. 
Tabel 1. Pertanyaan dan jawaban sesi tanya-jawab

\begin{tabular}{ll}
\hline No & \multicolumn{1}{c}{ Pertanyaan } \\
\hline 1. & $\begin{array}{l}\text { Apakah perbedaan amlodipin dan } \\
\text { captopril? (Ibu Nawa) }\end{array}$ \\
2. & $\begin{array}{l}\text { Apakah penggunaan obat } \\
\text { antihipertensi harus berlanjut? (Ibu }\end{array}$ \\
3. & $\begin{array}{l}\text { Sumardi) } \\
\text { Apakah ada obat antihipertensi } \\
\text { yang menyebabkan batuk? (Ibu } \\
\text { Bambang) }\end{array}$
\end{tabular}

4. Lebih baik menggunakan captopril $12,5 \mathrm{mg}$ atau captopril $25 \mathrm{mg}$ ? (Ibu Dartin)

5. Kapan penggunaan TOGA pada hipertensi? (Ibu Kuswaningsih)

6. Apakah vertigo bisa menyebabkan hipertensi? (Ibu Tutik)

Jawaban

Amlodipin dan captopril merupakan obat antihipertensi tetapi berbeda golongan.

Obat antihipertensi harus digunakan rutin dan berkelanjutan mulai dari dosis terendah.

Ada. Obat antihipertensi golongan ACEi seperti captopril umumnya menyebabkan batuk kering. Batuk kering tersebut merupakan salah satu efek samping dari penggunaan obat captopril. Obat golongan ACEi sebaiknya tidak direkomendasikan pada pasien asma.

Penggunaan obat antihipertensi dimulai dari dosis terendah. Apabila pada dosis terendah tidak menunjukkan efek yang lebih baik, maka perlu peningkatan dosis.

Penggunaan TOGA sebagai terapi pencegahan, sehingga bisa diberikan ketika pasien mengalami prehipertensi.

Vertigo tidak selalu berhubungan dengan hipertensi. Akan tetapi, 20\% kasus vertigo dikarenakan hipertensi.

\section{Hasil dan Pembahasan}

Keberlanjutan dari acara penyuluhan dilakukan analisis soal post-test dan soal pre-test untuk mengetahui apakah ada peningkatan pemahaman setelah materi disampaikan. Hasil nilai pretest dan post test yang dikerjakan oleh ibu-ibu PKK Danukusuman disajikan dpada Tabel 2. Nilai tersebut selanjutnya dilakukan uji t menggunakan SPSS dan didapatkan nilai signifikansi 0,001 $(<0,05)$ sehingga ada perbedaan yang signifikan antara hasil pre-test dengan post-test. Hal tersebut menunjukkan bahwa kegiatan pengabdian kepada masyarakat yang telah dilakukan mampu memberikan manfaat dan pemahaman kepada ibu-ibu PKK Danukusuman mengenai hipertensi, cara DAGUSIBU obat antihipertensi, serta pemanfaatan TOGA untuk hipertensi.

Tabel 2. Hasil pre-test dan post-test

\begin{tabular}{|c|c|c|c|c|c|}
\hline \multirow{2}{*}{ No } & \multirow{2}{*}{ Nama } & \multirow{2}{*}{ Usia (th) } & \multirow{2}{*}{ Pekerjaan } & \multicolumn{2}{|c|}{ Nilai } \\
\hline & & & & Pre-test & Post-test \\
\hline 1 & Wiwik & 54 & Swasta & 8 & 10 \\
\hline 2 & Bu Bambang & 55 & Pedagang & 10 & 10 \\
\hline 3 & Yuliati & 44 & Ibu Rumah Tangga & 9 & 10 \\
\hline 4 & Erniati & 51 & Ibu Rumah Tangga & 7 & 10 \\
\hline 5 & Tutik & 46 & Ibu Rumah Tangga & 9 & 10 \\
\hline 6 & Suwarni & 74 & Ibu Rumah Tangga & 9 & 10 \\
\hline 7 & Sukatri & 77 & Ibu Rumah Tangga & 9 & 6 \\
\hline 8 & Ummu Kasya Fitri & 30 & Ibu Rumah Tangga & 6 & 10 \\
\hline 9 & Tinah & 54 & Buruh & 8 & 10 \\
\hline 10 & Sri Qartini & 68 & Ibu Rumah Tangga & 8 & 10 \\
\hline 11 & Nawa & 38 & Ibu Rumah Tangga & 8 & 9 \\
\hline 12 & Kateni & 44 & Ibu Rumah Tangga & 7 & 10 \\
\hline 13 & Ibu Sumardi & 80 & - & 6 & 9 \\
\hline 14 & Rini Astuti & 45 & - & 7 & 9 \\
\hline 15 & Ibu Dartin & 71 & Ibu Rumah Tangga & 7 & 8 \\
\hline 16 & Kuswaningsih & 44 & Ibu Rumah Tangga & 9 & 10 \\
\hline 17 & Riana Budi & 44 & - & 9 & 10 \\
\hline \multirow[t]{4}{*}{18} & Ningsih & 33 & - & 8 & 9 \\
\hline & & & Rata-rata \pm SD & $8,0 \pm 1,14$ & $9,4 \pm 1,04$ \\
\hline & & & Nilai Terbaik & 10 & 10 \\
\hline & & & Nilai Terendah & 6 & 6 \\
\hline
\end{tabular}



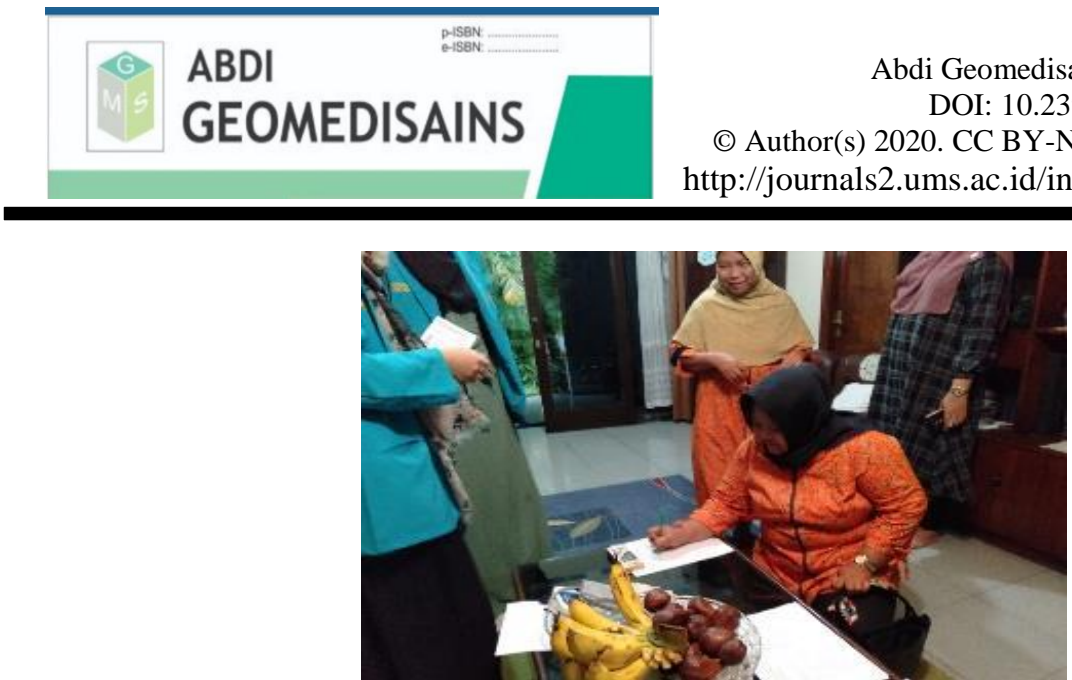

Gambar 1. Peserta PKK Danukusuman mengisi presensi penyuluhan
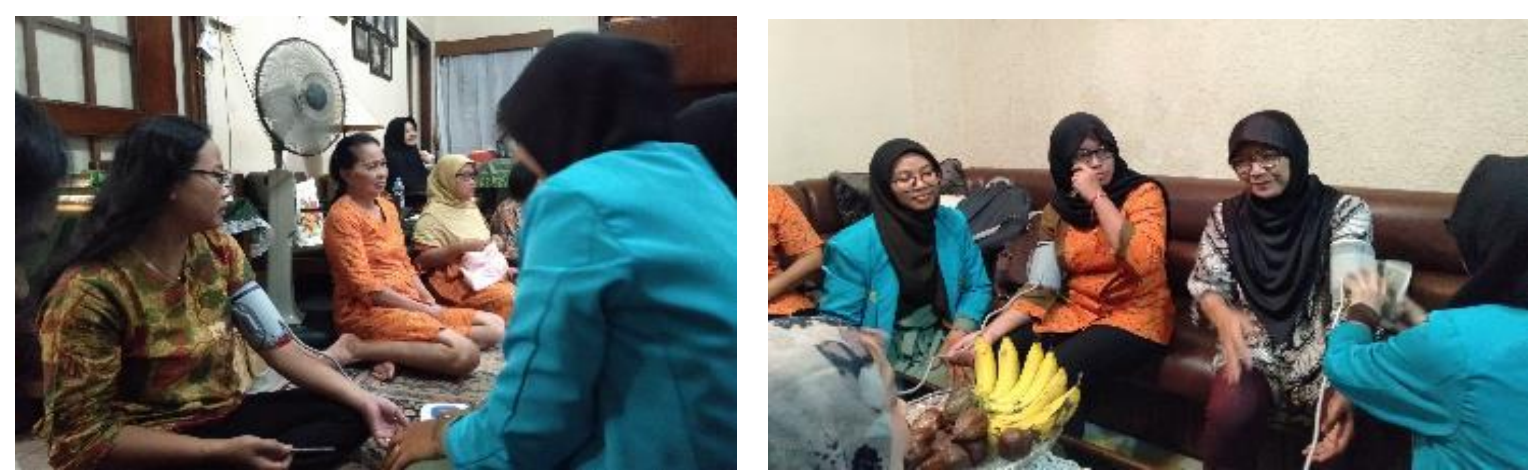

Gambar 2. Peserta PKK Danukusuman melakukan cek tekanan darah
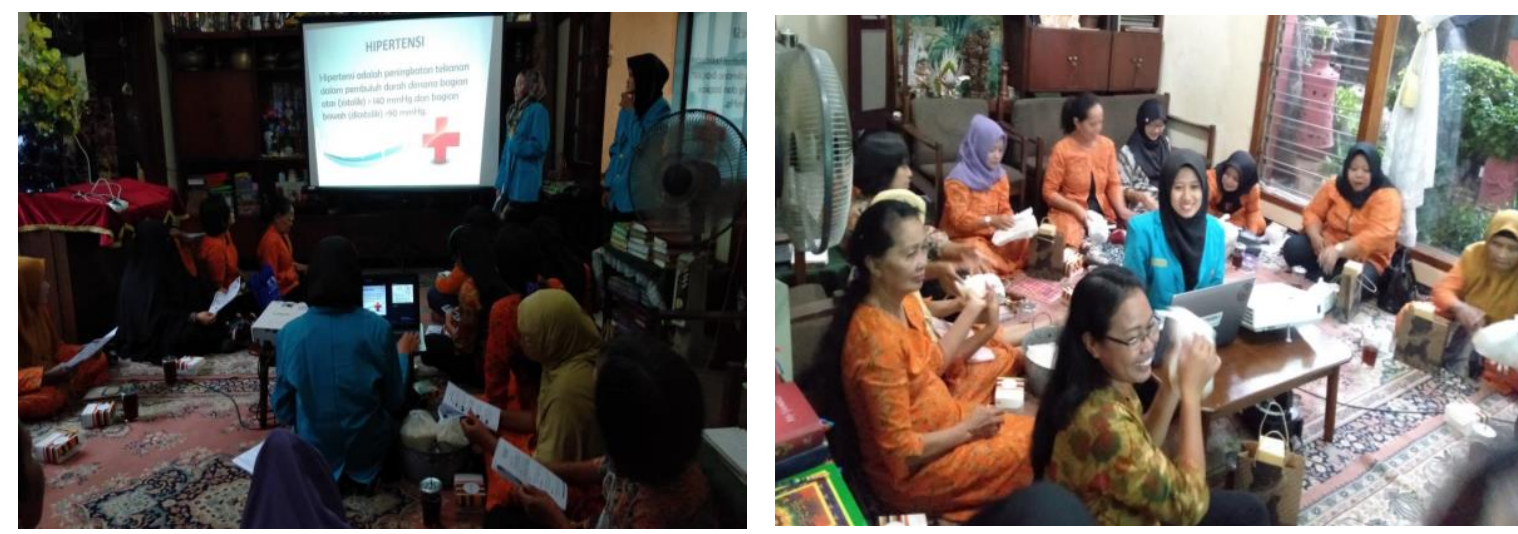

Gambar 3. Kegiatan penyuluhan pada peserta PKK Danukusuman
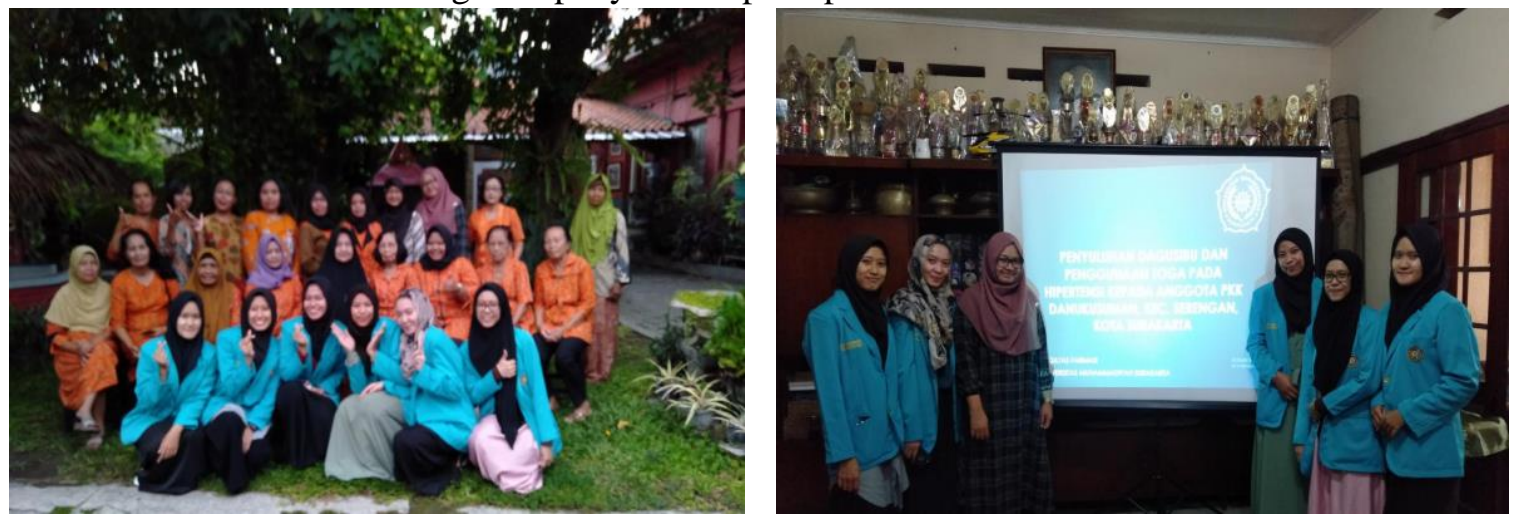

Gambar 4. Foto bersama PKK Danukusuman dan tim pelaksana pengabdian kepada masyarakat 
Kegiatan pengabdian masyarakat ini dapat dilaksanakannya kembali dengan tema pembahasan yang berbeda, dari pertanyaan yang diajukan terkait usulan tema untuk penyuluhan berikutnya diusulkan tema yaitu penyakit degeneratif tulang dan sendi, asam urat, serta kolesterol yang diderita oleh masyarakat setempat sehingga diperlukan pengetahuan tentang penyakit tersebut.

\section{Simpulan}

Pengabdian kepada masyarakat yang dilakukan pada ibu-ibu PKK Danukusuman mampu memberikan manfaat dan pemahaman kepada ibu-ibu PKK Danukusuman mengenai hipertensi, cara DAGUSIBU obat antihipertensi, serta pemanfaatan TOGA untuk hipertensi.

\section{Persantunan}

Ucapan terima kasih kami berikan kepada: Universitas Muhammdiyah Surakarta yang telah mendukung terlaksananya program ini melalui PID (Pengembangan Individu Dosen) Pengabdian Kepada Masyarakat dan ibu-ibu PKK Danukusuman Kota Surakarta yang telah menyediakan tempat untuk terselenggaranya program penyuluhan ini.

\section{Referensi}

Azhar, Isroul. (2017). Gambaran karakteristik pasien hipertensi di Puskesmas Gamping I Sleman Yogyakarta. Yogyakarta.

BPOM. (2015). Materi Edukasi Tentang Peduli Obat dan Pangan Aman. Jakarta: BPOM.

Dinas Kesehatan Surakarta. (2017). Profil Kesehatan Kota Surakarta Tahun. 2016. Surakarta:

Dinas Kesehatan Surakarta.

Kementerian Kesehatan RI. (2018). Laporan Nasional RISKESDAS 2018. Jakarta.

Lacy F.C., et al. (2009). Drug Information Handbook, 17 ${ }^{\text {th }}$. Lexy-comp for the American Pharmacists Association.

Mills, K. T. et al. (2016). Global Disparitas of hypertension Prevalence and Control; A Systematic Analysis of Population- Based Studies from 90 Countries. Circulation, 134(doi: 10.1161), pp. 441-450.

Ulung, P. S. (2014). Sehat Alami dengan Herbal 250 Tanaman Herbal Berkhasiat Obat +60 Resep Menu Kesehatan. Jakarta: PT Gramedia Pustaka Utama.

WHO. (2013). A Global Brief on Hypertension, Switzerland: World Health Organization.

\section{c) $9 \Theta \Theta$}

(C) 2020 by the authors. Submitted for possible open access publication under the terms and conditions of the Creative Commons Attribution (CC-BY-NC-ND) license (http://creativecommons.org/licenses/by/4.0/). 